\title{
Controlled Release of 5-Fluorouracil from Alginate Beads Encapsulated in 3D Printed pH-Responsive Solid Dosage Forms
}

\author{
Christos I. Gioumouxouzis, ${ }^{1}$ Aikaterini-Theodora Chatzitaki, ${ }^{1}$ Christina Karavasili, ${ }^{1}$ Orestis L. Katsamenis, ${ }^{2}$ \\ Dimitrios Tzetzis, ${ }^{3}$ Emmanouela Mystiridou, ${ }^{4,5}$ Nikolaos Bouropoulos, ${ }^{4,5}$ and Dimitrios G. Fatouros ${ }^{1,6}$
}

\begin{abstract}
Three-dimensional printing is being steadily deployed as manufacturing technology for the development of personalized pharmaceutical dosage forms. In the present study, we developed a hollow $\mathrm{pH}$-responsive 3D printed tablet encapsulating drug loaded non-coated and chitosan-coated alginate beads for the targeted colonic delivery of 5fluorouracil (5-FU). A mixture of Eudragit ${ }^{\circledR}$ L100-55 and Eudragit ${ }^{\circledR}$ S100 was fabricated by means of hot-melt extrusion (HME) and the produced filaments were printed utilizing a fused deposition modeling (FDM) 3D printer to form the $\mathrm{pH}$-responsive layer of the tablet with the rest comprising of a water-insoluble poly-lactic acid (PLA) layer. The filaments and alginate particles were characterized for their physicochemical properties (thermogravimetric analysis, differential scanning calorimetry, X-ray diffraction), their surface topography was visualized by scanning electron microscopy and the filaments' mechanical properties were assessed by instrumented indentation testing and tensile testing. The optimized filament formulation was 3D printed and the structural integrity of the hollow tablet in increasing $\mathrm{pH}$ media ( $\mathrm{pH} 1.2$ to $\mathrm{pH} 7.4$ ) was assessed by means of time-lapsed microfocus computed tomography $(\mu \mathrm{CT})$. In vitro release studies demonstrated controlled release of 5 -FU from the alginate beads encapsulated within the hollow $\mathrm{pH}$-sensitive tablet matrix at $\mathrm{pH}$ values corresponding to the colonic environment ( $\mathrm{pH}$ 7.4). The present study highlights the potential of additive manufacturing in fabricating controlled-release dosage forms rendering them pertinent formulations for further in vivo evaluation.
\end{abstract}

KEY WORDS: three-dimensional printing; microfocus computed tomography; colonic delivery; alginate beads; 5-FU.

\footnotetext{
$\overline{{ }^{1} \text { Laboratory of Pharmaceutical Technology, School of Pharmacy, }}$ Aristotle University of Thessaloniki, GR-54124, Thessaloniki, Greece.

${ }^{2} \mu$-VIS X-Ray Imaging Centre, Faculty of Engineering and the Environment, University of Southampton, Southampton, SO17 1BJ, UK.

${ }^{3}$ School of Science and Technology, International Hellenic University, 14km Thessaloniki - N. Moudania, GR57001, Thermi, Greece.

${ }^{4}$ Foundation for Research and Technology Hellas, Institute of Chemical Engineering and High Temperature Chemical Processes, Patras, Greece.

${ }^{5}$ Department of Materials Science, University of Patras, 26504, Rio, Patras, Greece.

${ }^{6}$ To whom correspondence should be addressed. (e-mail: dfatouro@pharm.auth.gr)
}

\section{INTRODUCTION}

The recent emergence of personalized medicine has raised the demand for pharmaceutical formulations tailored to meet specific patient needs. At the same time, the research focus of the pharmaceutical industry has been directed on the development of more sophisticated dosage forms to maximize therapeutic efficacy and eliminate side effects by obviating time-consuming and expensive procedures. To this end, 3D printing (additive manufacturing) has been found to successfully meet these requirements. An array of different techniques, namely powder bed printing (PBP), selective laser sintering (SLS), stereolithography (SLA), inkjet printing (IP) and fused deposition modeling (FDM), have been previously explored for the development of pharmaceutical formulations $(1,2)$. Most of research work has focused on the implementation of FDM 3D printing because it is a costeffective, time-saving and versatile method of creating complex solid structures. 
FDM technology has found numerous applications in the development of 3D printed formulations that either incorporate the API within a polymer matrix (3-6) or encapsulate the API or the API-loaded carriers in complex polymer structures $(7,8)$. The second category exploits the ability of FDM $3 \mathrm{D}$ printing in developing objects with elaborate shapes, cavities and compartments consisting of different polymers with varying properties. As such, these formulations can be used to modify the release characteristics of the drugs and enable targeted drug delivery at desired sites of the gastrointestinal tract (GIT) (7).

Marine polysaccharides have been extensively utilized in pharmaceutical and cosmetic applications due to their favorable properties, among which their biocompatibility and biodegradability, cost-effectiveness and safety. They are commonly extracted from plants such as algae (sodium alginate) or animals such as crustaceans (chitosan). It has been demonstrated that these biopolymers exhibit a $\mathrm{pH}-$ dependent sensitivity as well as mucoadhesive properties, constituting them pertinent candidates for site-specific oral drug delivery applications. Alginate, a linear polysaccharide composed of alternating blocks of $\beta(1 \rightarrow 4)$ linked Dmannuronic acid and $\alpha(1 \rightarrow 4)$ linked L-guluronic acid residues, is amenable to ionic crosslinking forming threedimensional networks that remain intact in the acidic gastric environment and start to dissolve under neutral and alkaline $\mathrm{pH}$ conditions (9). In this context, alginate has been extensively evaluated for enhancing the therapeutic efficacy of orally administered colon-specific drug delivery systems.

Several formulation approaches have been adopted using chitosan/alginate carriers containing 5-fluorouracil (5FU) for local colonic delivery, enrolling microspheres (1012), microparticles (13-15), micelles (16), nanocomplexes (17) and nanoflowers (18), in an attempt to control the release profile of the active substances.

The aim of the present study was the development of a $\mathrm{pH}$-responsive 3D printed dosage form for the controlled delivery of 5-FU at a $\mathrm{pH}$ corresponding to the colonic environment, minimizing any release of the active at lower $\mathrm{pH}$ values $(\mathrm{pH} 1.2$ and $\mathrm{pH}$ 6.8) in an attempt to achieve targeted drug delivery. Moreover, the formulation should possess properties that make feasible its convenient and rapid personalization by in situ modifying the drug content of each dosage form batch. In that perspective, a hollow 3D printed tablet was fabricated comprising of an insoluble upper polylactic acid (PLA) matrix with its bottom part replaced by a thin layer of a mixture of Eudragit ${ }^{\circledR}$ L100-55 and Eudragit ${ }^{\circledR}$ S100 (polymethacrylates soluble above $\mathrm{pH} 5.5$ and 7.0, respectively). Polymethacrylates of different grades (Eudragit ${ }^{\circledR}$ L100-55 (19), L100 (20), E (21), RL (8,22,23), RS (22)) have been previously used as carriers in pharmaceutical applications of FDM 3D printing due to their versatility and $\mathrm{pH}$-responsive nature. Especially, Eudragit ${ }^{\circledR}$ L100-55 has been employed in the manufacturing of FDM 3D printed gastro-resistant tablets, by applying the enteric coating via a second printer nozzle, as a continuous onestage procedure (19). Alginate beads loaded with 5-FU, a chemotherapeutic API used in the treatment of colon cancer, were introduced in the hollow 3D printed dosage form. The objective of the study was to demonstrate that gradual erosion of the Eudragit ${ }^{\circledR}$ layer in conditions simulating the
GIT transit of the dosage form could achieve colon-specific 5FU delivery from the alginate beads (24). Delivery of 5-FU in the colon is desired in order to avoid off-target toxicity against small intestinal epithelium and to reduce the risk of myelosuppression induced by high API concentration in the blood circulation, due to the fact that 5-FU absorption from the colon is slower in comparison to the small intestine, resulting in reduced $C_{\max }$ and prolonged $t_{1 / 2}$ API values $(25,26)$.

The developed $\mathrm{pH}$-responsive 3D printed dosage form can facilitate the simultaneous delivery of distinctive multiparticulate dosage forms distributed within the interior hollow matrix, the personalization of the administered drug dose by adjusting the encapsulated particulate dosage forms, while at the same time prevent dose dumping or release of the drug at unwanted GI sites, due to possible defects in certain spots of the formulation. Combination of the above characteristics of multiparticulate dosage forms and the manufacturing versatility of $3 \mathrm{D}$ printing demonstrate the advantages of the presented formulation as a promising 5FU carrier for the treatment of colorectal cancer.

\section{MATERIALS AND METHODS}

\section{Materials}

Alginate acid sodium salt, low molecular weight chitosan (MW 50,000-190,000 Da, 75-85\% deacetylated), 5-FU and triethyl citrate (TEC) were purchased from Sigma-Aldrich Co Ltd (Germany). Calcium chloride was purchased from FERAK (Berlin GmbH). Eudragit ${ }^{\circledR}$ L100-55 and S100 were purchased from Evonik AG (Germany). PLA filament (1.75 mm diameter, print temperature $180-220{ }^{\circ} \mathrm{C}$, density $1.24 \mathrm{~g} / \mathrm{mL}$, RoHS compliant) was purchased from FormFutura VOF (the Netherlands). All chemicals were of analytical grade. Distilled water was used in all experimental procedures.

\section{Preparation of Plain and Chitosan-Coated Alginate Beads}

Sodium alginate $(2 \% w / v)$ and 5 -FU were dissolved in distilled water in a mass ratio of 2:1. The solution was injected into $200 \mathrm{mM}$ calcium chloride solution using a 40-mmdiameter syringe. The syringe distance from the surface of the calcium chloride solution was set at $5 \mathrm{~cm}$ and the stirring speed of the solution at $100 \mathrm{rpm}$. After $20 \mathrm{~min}$, the beads were collected by filtration and washed with distilled water. The beads were then dried at $37{ }^{\circ} \mathrm{C}$ for 3 days to ensure complete removal of moisture. Chitosan-coated alginate beads were prepared by submerging the freshly prepared alginate beads in a $0.1 \% \mathrm{w} / v$ or $0.5 \% \mathrm{w} / v$ chitosan solution, respectively, under mild magnetic stirring for $15 \mathrm{~min}$. The chitosan-coated beads were collected by filtration, washed with distilled water, and further dried at $37{ }^{\circ} \mathrm{C}$ for 3 days.

For the determination of 5-FU loading in the alginate beads, a specific quantity of the beads (1 mg) was added in $10 \mathrm{~mL}$ of citric acid and allowed to stir for $2 \mathrm{~h}$. The solution was centrifuged for $15 \mathrm{~min}$ at $4500 \mathrm{rpm}$, syringed filtered and 5-FU quantification was performed with UVspectrophotometry at $266 \mathrm{~nm}$. 


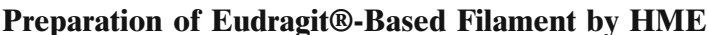

Different combinations of Eudragit ${ }^{\circledR}$ L100-55/S100 and plasticizer (TEC) (Table I) were blended and fed into a single-screw extruder (Filabot Original ${ }^{\circledR}$, Filabot Inc., VT, USA). The extruder was operated at $35 \mathrm{rpm}$ and the mixtures were extruded at $150{ }^{\circ} \mathrm{C}$ (except from F1 extruded at $165^{\circ} \mathrm{C}$ ) through a 1.5-mm nozzle. A 1:4 ratio of TEC:Eudragit ${ }^{\circledR}$ L100-55 was employed in order to decrease $T_{\mathrm{g}}$ of the polymer and facilitate extrusion (27). Higher TEC percentage and HME temperature were required when increasing Eudragit ${ }^{\circledR}$ S100 content, as that type of polymethacrylate exhibits increased $T_{\mathrm{g}}$ value $\left(173{ }^{\circ} \mathrm{C}\right)$ compared to Eudragit ${ }^{\circledR}$ L100$55\left(111^{\circ} \mathrm{C}\right)(28)$.

\section{D Printing of pH-Responsive Dosage Forms}

3D printed dosage forms were designed using AutoCAD ${ }^{\circledR} 2016$ (Autodesk Inc., USA) and exported as .stl files to Makerware ${ }^{\circledR}$ software version 3.9.2 (MakerBot Inc., USA), (Fig. 1a, b). The preferred design was flat cylindrical with smoothed edges consisting of two layers, an upper water-insoluble PLA layer and a lower Eudragit-based layer.

The dimensions of the $3 \mathrm{D}$ printed dosage forms were calculated considering the need for adequate space for beads' hosting inside them. Infill was arbitrary set to $30 \%$, three shells were employed to ensure lateral impermeability of the dosage form and diameter was set to be $1.5 \mathrm{~cm}$. The desired height $(h)$ of the empty internal region of the formulation was calculated to be $3 \mathrm{~mm}\left(V=\pi r^{2} h\right)$. An additional $1.2 \mathrm{~mm}$ of solid PLA roof was added to increase the weight of the pill to ensure sinking of the solid dosage form in the medium.

Minimum effective thickness of enteric coatings employed in traditional coating methods ranges between 30 $\mu \mathrm{m}$ and $100 \mu \mathrm{m}$ (29). Nevertheless, FDM-created layers present a significantly different behavior compared to these traditionally created coating layers, demanding increased layer thickness in order to ensure limited water permeability at undesired $\mathrm{pH}$ values (19). Therefore, $200 \mu \mathrm{m}$ was chosen as the thickness of the Eudragit@-based layer (Fig. 1f) and the final height of the formulation was $4.4 \mathrm{~mm}(1.2 \mathrm{~mm}$ solid roof $+3 \mathrm{~mm}$ cell compartment $+0.2 \mathrm{~mm}$ bottom gastroresistant layer).

It should be mentioned that MakerBot ${ }^{\circledR}$ software allows only one infill value for both nozzles. Moreover, upper PLA layer should be constructed without floor to allow release of the beads after the dissolution of the Eudragit ${ }^{\circledR}$ layer. To

Table I. Composition ( $\% w / w)$ of the gastro-resistant filament formulations

\begin{tabular}{lccc}
\hline Formulation & Eudragit $^{\circledR}$ L100-55 & Eudragit $^{\circledR}$ S100 & TEC \\
\hline F1 & 78 & 0 & 22 \\
F2 & 73 & 5 & 22 \\
F3 & 68 & 10 & 22 \\
F4 & 50 & 25 & 25 \\
F5 & 0 & 65 & 35 \\
\hline
\end{tabular}

overcome these problems, infill was set to $30 \%$, whereas floor thickness and roof thickness settings were adjusted to 0 (to eliminate upper PLA compartment floor) and $1.2 \mathrm{~mm}$ (a value higher than Eudragit ${ }^{\circledR}$ layer thickness to ensure its printing), respectively.

Printing was performed in a MakerBot Replicator ${ }^{\circledR} 2 \mathrm{X}$ 3D printer (MakerBot Inc., NY, USA), using the first nozzle for printing Eudragit ${ }^{\circledR}$-based lower layer and the second nozzle for printing the PLA upper layer. The following settings were employed: (i) Eudragit ${ }^{\circledR}$-based layer printing nozzle: $T_{\text {print }}=182{ }^{\circ} \mathrm{C}$; (ii) PLA layer printing nozzle: $T_{\text {print }}=$ $215{ }^{\circ} \mathrm{C}$ and (iii) General: printing speed $=20 \mathrm{~mm} / \mathrm{s}$, first layer printing speed $=7 \mathrm{~mm} / \mathrm{s}$, travel speed $=150 \mathrm{~mm} / \mathrm{s}, T_{\text {platform }}=$ $115{ }^{\circ} \mathrm{C}$, infill density $=30 \%$, infill pattern $=$ diamond, layer height $=0.2 \mathrm{~mm}$, number of shells $=3$, floor thickness $=0 \mathrm{~mm}$, roof thickness $=1.2 \mathrm{~mm}$.

Raft and purging walls options were deactivated. To facilitate 3D printing, the following modifications were employed: (i) building plate was covered with Blue painter's tape (3M, MI, USA) to ensure proper adhesion of the Eudragit ${ }^{\circledR}$-based lower layer to the printing surface and (ii) printhead's feeding barrel was lubricated using TEC (SigmaAldrich, MI, USA-technical grade, 90\%), approximately every ten printings, in order to avoid jamming, caused by high friction between Eudragit@-based filament and barrel walls.

To achieve loading of 5-FU alginate beads into the formulation, printing was paused before completion $(30 \%$ infill), beads were evenly distributed into the hollow part of the PLA compartment and printing was resumed to complete the construction of the rest of the PLA compartment (roof with $100 \%$ infill). The diameter and thickness of the 3D printed formulations (Fig. 1c-e) were measured using an electronic caliper.

\section{Scanning Electron Microscopy Studies}

The morphological features of the extruded filaments, the $3 \mathrm{D}$ printed tablets and the alginate beads were assessed using a Zeiss SUPRA 35VP SEM microscope. Specimens were mounted on metallic sample stands using conductive adhesive tape (PELCO Image Tabs) and gold sputtered under high vacuum $\left(\sim 5 \times 10^{-2}\right.$ mbar $)$ using an Emitech K550X DC sputtering unit (Emitech Ltd. Ashford, Kent, $\mathrm{UK})$. The mean particle size was expressed as the mean diameter of 100 beads calculated from the SEM photos using the software Image Tool.

\section{Physicochemical Characterizations}

\section{Thermogravimetric Analysis}

Thermogravimetric analysis (TGA) was performed using a TGA Q500 (TA instruments Ltd.) apparatus with a heating rate of $10{ }^{\circ} \mathrm{C} / \mathrm{min}$ from $40{ }^{\circ} \mathrm{C}$ to $800{ }^{\circ} \mathrm{C}$ in air atmosphere.

\section{Differential Scanning Calorimetry}

The thermal behavior of the samples was analyzed on a 204 F1 Phoenix DSC apparatus (Netsch GmBH, Germany). Five milligrams of the samples were sealed in aluminum pans 

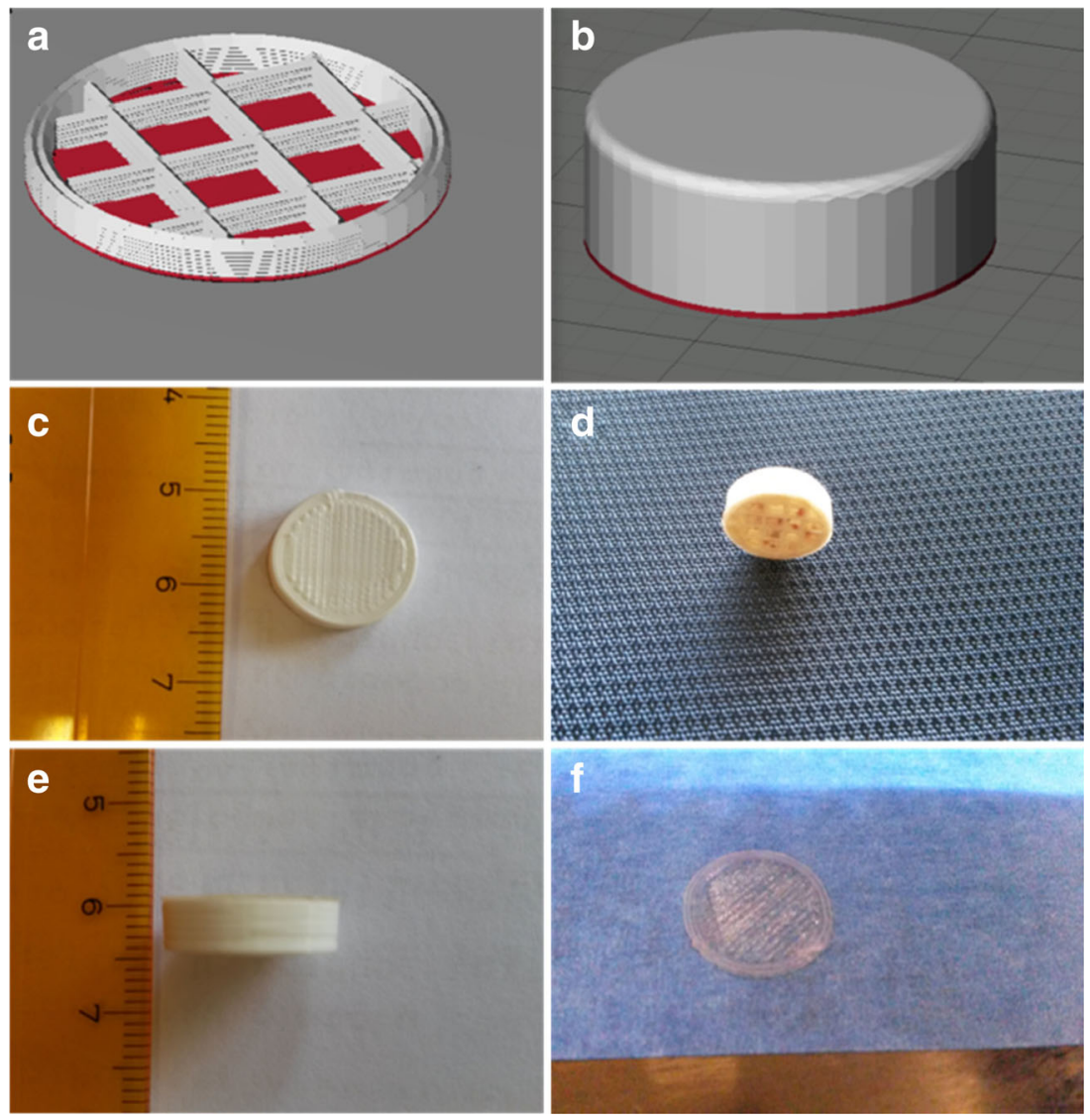

Fig. 1. Stereolithography images of the $\mathbf{a}$ inner and $\mathbf{b}$ outer structure of the dosage form. $\mathbf{c}$ Top, $\mathbf{d}$ bottom, e side images of the 3D printed dosage form and $\mathbf{f} 3 \mathrm{D}$ printed Eudragit ${ }^{\circledR}$ based monolayer image

with perforated lids and their differential scanning calorimetry (DSC) profiles were acquired from $30{ }^{\circ} \mathrm{C}$ to $350{ }^{\circ} \mathrm{C}$ at a heating rate of $10^{\circ} \mathrm{C} / \mathrm{min}$ under a nitrogen purge of $70 \mathrm{~mL} /$ min. The software used for DSC measurements was Proteus ver. 5.2.1 (Netsch GmBH, Germany).

\section{X-ray Powder Diffraction}

Sample crystallinity was evaluated using a powder X-ray diffractometer (D8-Advance, Bruker, Germany) with Nifiltered CuKa1 radiation $(\lambda=0.154059 \mathrm{~nm})$, operated at $40 \mathrm{kV}$ and $40 \mathrm{~mA}$. Samples were scanned from $5^{\circ}$ to $50^{\circ}$ at a step of $0.02^{\circ}$ and a scan speed of $0.35 \mathrm{~s} / \mathrm{step}$.

\section{Mechanical Tests}

Instrumented Indentation Testing. The mechanical properties of the PLA and the developed filament formulations were evaluated using instrumented indentation testing (IIT). Instrumented indentation is a powerful technique enabling local variations in modulus to be measured (30-32). Indentations were conducted on a dynamic ultra-micro-hardness tester (DUH-211; Shimadzu Co., Kyoto, Japan) fitted with a triangular pyramid indenter tip (Berkovich indenter). Ten force-indentation depth curves were recorded for each specimen using $208 \mathrm{mN}$ maximum load, $3 \mathrm{~s}$ dwell time to a depth of around 6-11 $\mu \mathrm{m}$ depending on the testing material.
Tensile Tests. Tensile tests were performed at room temperature $\left(23^{\circ} \mathrm{C}\right)$ on a Testometric (UK) universal testing machine equipped with a $50 \mathrm{kN}$ load cell at a constant crosshead speed of $0.5 \mathrm{~mm} / \mathrm{min}$. The modulus was calculated within the linear part of the stress-strain curves. All presented data correspond to the average of at least four measurements.

\section{Swelling Studies}

Swelling studies of the non-coated and the chitosancoated alginate dried beads were performed in simulated gastric fluid $\mathrm{pH} 1.2$ (SGF; $\mathrm{NaCl} 2 \mathrm{~g} / \mathrm{L}, 80 \mathrm{~mL} 1 \mathrm{M} \mathrm{HCl} / \mathrm{L}$ ), simulated intestinal fluid $\mathrm{pH} 6.8$ (SIF; $\mathrm{KH}_{2} \mathrm{PO}_{4} 6.805 \mathrm{~g} / \mathrm{L}$, $\mathrm{NaOH} 0.896 \mathrm{~g} / \mathrm{L}$ ) and phosphate-buffered saline $\mathrm{pH} 7.4$ (PBS; $\mathrm{KCl} 0.2 \mathrm{~g} / \mathrm{L}, \mathrm{K}_{2} \mathrm{HPO}_{4} 0.24 \mathrm{~g} / \mathrm{L}, \mathrm{NaCl} 8 \mathrm{~g} / \mathrm{L}, \mathrm{Na}_{2} \mathrm{HPO}_{4}$ $3.63 \mathrm{~g} / \mathrm{L}$ ) at $37{ }^{\circ} \mathrm{C}$ under magnetic stirring. A specified number of beads were periodically removed, blotted gently on filter paper to remove excess water, and weighed. Water uptake (\%) was calculated according to Eq. (1).

Water uptake $(\%)=$ Ws - Wo $/$ Wo $\times 100$

where Ws is the weight of the beads in the swollen state and Wo is the initial weight of the dried beads. 
Water uptake study of the non-coated alginate beads in phosphate buffer $\mathrm{pH} 7.4$ was terminated after 90 min because of the disintegration of the system, attributed to the ion exchange reaction between $\mathrm{Na}^{+}$(present in the phosphate buffer) and $\mathrm{Ca}^{2+}$ linked to the carboxylic groups of alginate.

\section{In Vitro Release Studies}

The in vitro release of 5-FU from the non-coated and chitosan-coated alginate beads was performed in SGF pH 1.2, SIF pH 6.8 and PBS pH 7.4. A specified amount of dried noncoated and chitosan-coated alginate beads (ranging from 5 $\mathrm{mg}$ to $10 \mathrm{mg}$ ) of equivalent 5 -FU content was added in $20 \mathrm{~mL}$ of each release medium at $37^{\circ} \mathrm{C}$ in an orbital shaking water bath. At predetermined time intervals, samples $(3 \mathrm{~mL})$ were withdrawn and replaced with an equal volume of the corresponding prewarmed buffer solution. Samples were syringe filtered and the concentration of 5-FU was quantified with UV spectroscopy at $266 \mathrm{~nm}$.

The in vitro release of $5-\mathrm{FU}$ from the $3 \mathrm{D}$ printed tablets containing the non-coated or the chitosan-coated alginate beads was performed in conical flasks in $100 \mathrm{~mL}$ of release medium at $37{ }^{\circ} \mathrm{C}$ in an orbital shaking water bath. The $\mathrm{pH}$ of medium was gradually increased; during the first $2 \mathrm{~h}$, release study was conducted in SGF pH 1.2, during the next $2 \mathrm{~h}$ in SIF pH 6.8 and till the end of the experiment in PBS pH 7.4. At predetermined time intervals, samples $(1 \mathrm{~mL})$ were withdrawn and replaced with an equal volume of the corresponding prewarmed buffer solution.

\section{Time-Lapsed X-ray Microfocus Computed Tomography}

Time-lapsed X-ray microfocus computed tomography $(\mu \mathrm{CT})$ was used to assess the alginate bead swelling and the dissolution behavior of the printed dosage forms during consequent exposure in media that simulated exposure to gastrointestinal environment. The volumetric imaging was conducted on a 3D printed dosage form containing nonchitosan-coated alginate beads and comprised of four $\mu \mathrm{CT}$ scans as outlined below:

Scan 1: native state (dry); Scan 2: imaging after a $2 \mathrm{~h}$ exposure in SGF ( $\mathrm{pH}$ 1.2); Scan 3: imaging after a $2 \mathrm{~h}$ exposure in SIF ( $\mathrm{pH}$ 6.8); Scan 4: imaging after a $5 \mathrm{~h}$ exposure in PBS ( $\mathrm{pH} 7.4)$.

$\mu \mathrm{CT}$ imaging was performed using a Nikon's Med-X prototype $\mu \mathrm{CT}$ scanner (33) at $80 \mathrm{kVp} / 212 \mu \mathrm{A}$ using a molybdenum (Mo) target and no beam pre-filtration. The scanner is equipped with a $2000 \times 2000$ pixel detector and the source-to-detector and source-to-object distances were 992.02 and $49.57 \mathrm{~mm}$ respectively, resulting in a voxel size of $0.010 \mathrm{~mm}^{3}$. In all cases, the sample was placed on a plastic post and a total of 2001 radiographs were collected with an angular step of 0.143 degrees over a 360-degree rotation of the sample. Following the acquisition, the raw data were reconstructed using Nikon's reconstruction software (CT Pro 3D; v5.1.6407.25107), which uses a filtered back projection algorithm and exported as 32-bit .raw volumes. The 32-bit volumes were flowingly imported into Fiji/ImageJ (34) where a $3 \mathrm{D}(2 \times 2 \times 2$ pixels $)$ median filter was used to reduce noise and a mild $(\sigma$ blur radius $=2$ ) unsharp mask was applied to enhance the edges after denoising. Finally, Volume Graphics VGStudioMAX was used for visualization.

\section{Statistical Analysis}

Data were analyzed using Student's $t$ test. Significance level was set at $p<0.05$.

\section{RESULTS AND DISCUSSION}

\section{HME Procedure}

HME of filaments containing Eudragit ${ }^{\circledR}$ L100-55 (F1F4) was conducted at $150{ }^{\circ} \mathrm{C}$. Relatively elevated temperature was necessary due to the high $T_{\mathrm{g}}$ of the material, even when high amounts of plasticizer (22-25\%) were employed. Rising HME temperature at $160{ }^{\circ} \mathrm{C}$ resulted in color change of the filament (from yellow/white to orange/brown) indicating material degradation. Filament consisting only of Eudragit ${ }^{\circledR}$ S100 required not only excessive amount of plasticizer $(35 \%)$ but also higher temperatures $\left(165^{\circ} \mathrm{C}\right)$ for successful extrusion. No filament discoloration was observed at that temperature for F5. Filament pieces with acceptable diameter variation $(1.75 \pm 0.07 \mathrm{~mm})$ were selected and stored in sealed plastic bags.

\section{Printing Procedure}

Different filament formulations (F1-F5) were printable at $182{ }^{\circ} \mathrm{C}$. Filaments deriving from F1, F2 and F3 (containing high Eudragit ${ }^{\circledR}$ L100-55 percentage) were found to be brittle and unsuitable for reproducible $3 \mathrm{D}$ printing when TEC was used in a final concentration of $20 \%$ or less, whereas addition of $\geq 25 \%$ of the plasticizer resulted in soft filament that deformed from the stress induced by the loading gears of the printhead, resulting in printing failure. Therefore, $22 \%$ TEC was chosen as the most suitable TEC percentage. Elevated printing bed temperatures (above $110{ }^{\circ} \mathrm{C}$ ) and low printing speed $(<10 \mathrm{~mm} / \mathrm{s})$ were necessary to achieve proper adhesion of the printing material onto the printing surface. PLA showed good adhesion onto the Eudragit ${ }^{\circledR}$-based layer. Incorporation of higher percentages of Eudragit ${ }^{\circledR}$ S100 improved gradually the printing performance. This behavior could be explained by the fact that adding components with higher $T_{\mathrm{m}}$ has shown to improve solidification of 3D printed structures (21) (raw Eudragit ${ }^{\circledR} \mathrm{S} 100$ has a $\sim 60{ }^{\circ} \mathrm{C}$ higher melting point compared to Eudragit ${ }^{\circledR}$ L100-55 (28)).

Moreover, construction of monolayers with sufficient fusion between polymeric strands was feasible only for the first layer (probably attributed to the heated bed and the absolute smoothness of the underlying surface). On the contrary, lateral or top surfaces require at least three layers of standard thickness (or $>0.52 \mathrm{~mm}$ ) material to become water impermeable (19). Therefore, constructing the dosage form with Eudragit ${ }^{\circledR}$-based walls of different thicknesses could result in irregular or biphasic dissolution patterns, attributed to the water intrusion at varying times from different sides of the formulation. Consequently, two-layered manufacturing approach for our dosage form was chosen to achieve one-directional erosion of the polymethacrylate layer. 


\section{SEM Analysis}

The morphological properties of the dry alginate beads (non-coated, chitosan-coated) were examined using SEM analysis. All particles demonstrated a spherical shape and a solid internal structure as shown in Fig. 2. Chitosan-coated alginate beads (Fig. 2c, e) demonstrated a smoother surface topography compared to uncoated alginate beads (13). Alterations in the textural properties of alginate beads upon chitosan coating have been previously demonstrated and justified by the interactions developed between alginate and the polyelectrolyte (35). The non-coated alginate beads demonstrated a larger size $(1.01 \pm 0.11 \mathrm{~mm})(t$ test, $p<0.05)$ compared to the $0.1 \% \mathrm{w} / \mathrm{v}(0.92 \pm 0.12 \mathrm{~mm})$ and the $0.5 \% \mathrm{w} / \mathrm{v}$ $(0.83 \pm 0.09 \mathrm{~mm})$ chitosan-coated alginate beads. Chitosan coating induced a slight shrinkage of the alginate beads, due to the formation of a closed network between alginic acid and chitosan, as previously reported (35). The presence of 5-FU
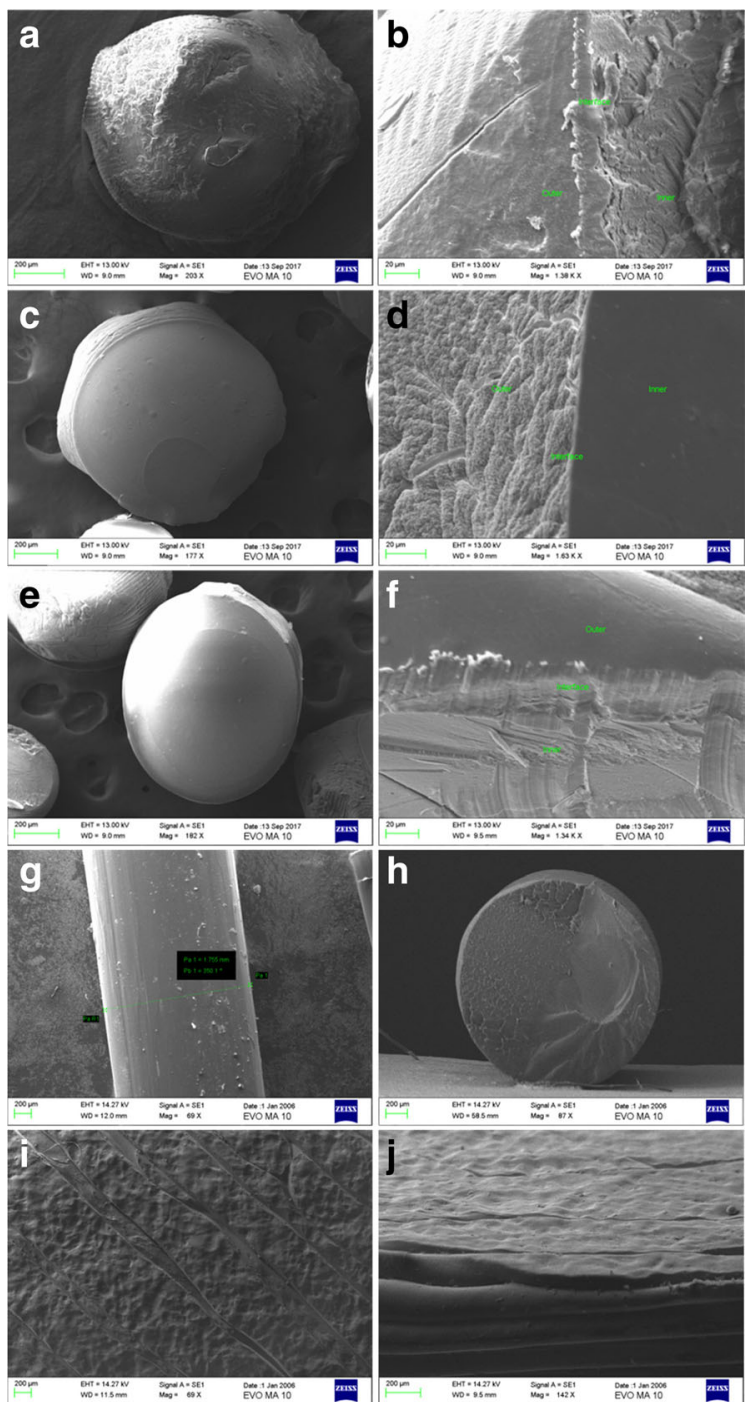

Fig. 2. SEM images of a 5-FU alginate beads, c 5-FU alginate beads coated with $0.1 \% w / v$ chitosan, e 5-FU alginate beads coated with $0.5 \% w / v$ chitosan and $\mathbf{b}$, d, f their corresponding cross sections, $\mathbf{g}$ Eudragit@-based filament lateral view, h Eudragit@-based filament cross section, i 3D printed dosage form bottom view, j 3D printed dosage form PLA-Eudragit ${ }^{\circledR}$ contact point (bottom-lateral view) did not significantly affect ( $t$ test, $p>0.05$ ) the particle size which followed the same trend as the non-coated and chitosan-coated alginate beads (Fig. 3).

SEM images of the produced F3 Eudragit ${ }^{\circledR}$-based filaments are shown in Fig. $2 \mathrm{~g}, \mathrm{~h}$ and reveal the smooth external surface and the solid, homogenous and compact internal structure of the produced filaments. Complete fusion between the 3D printed polymeric strands (Fig. $2 \mathrm{i}$ ) resulted in the creation of an impermeable to water, smooth first Eudragit ${ }^{\circledR}$-based layer, where no pores and gaps were observed. Additionally, an excellent adhesion between the first Eudragit@-based layer and the overlying PLA layers ensured proper sealing of the hollow dosage form, as depicted in Fig. 2j.

\section{Determination of 5-FU Loading of Alginate Beads}

The ionic gelation method was used for the preparation of the 5-FU-loaded alginate beads. The drug loading of the non-coated alginate beads was calculated to be $2.04 \pm 0.37 \%$, compared to the $0.54 \pm 0.28 \%$ and $0.53 \pm 0.27 \%$ for the $0.1 \%$ $w / v$ and $0.5 \% w / v$ chitosan-coated alginate beads, respectively. The relatively low loading efficiency of low molecular weight drugs within the alginate beads accounts for the fast drug diffusion in the preparation medium, with the effect being more pronounced for the chitosan-coated formulations (13).

\section{Thermogravimetric Analysis}

Thermogravimetric analysis (TGA) was employed to determine the water content and polymer stability upon heating. The TGA thermograms of the raw materials and the alginate bead formulations are shown in Fig. 4a. The first stage of weight loss is attributed to water evaporation and appears in the range between $40{ }^{\circ} \mathrm{C}$ and $180{ }^{\circ} \mathrm{C}$ for all alginate bead formulations, with all formulation types presenting $c a .10 \%$ of water content. The weight loss of chitosancoated alginate beads increased with increasing chitosan content from $0.1 \% w / v$ to $0.5 \% w / v$, verifying the successful polyelectrolyte coating on the bead surface (36).

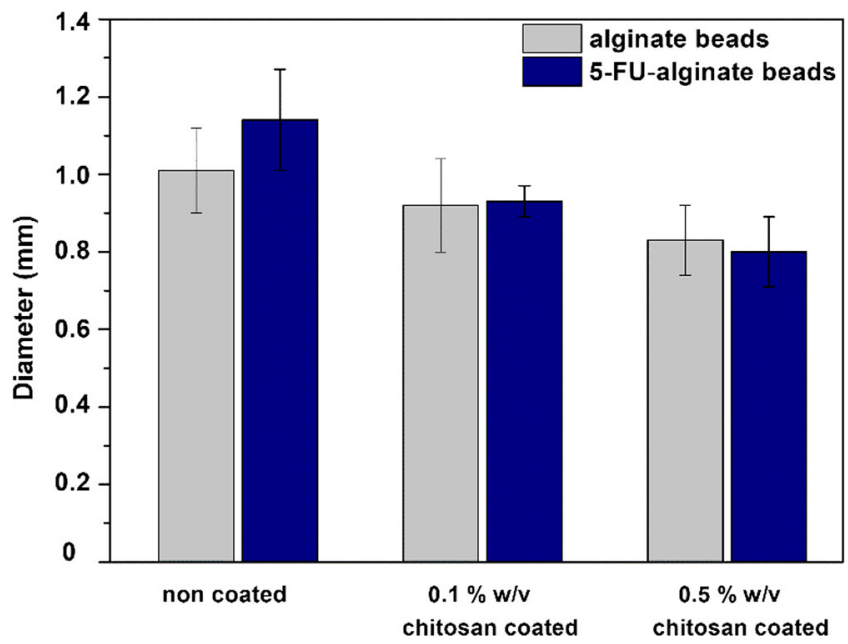

Fig. 3. Particle size of non-coated and chitosan-coated alginate beads before and after 5-FU loading 
a

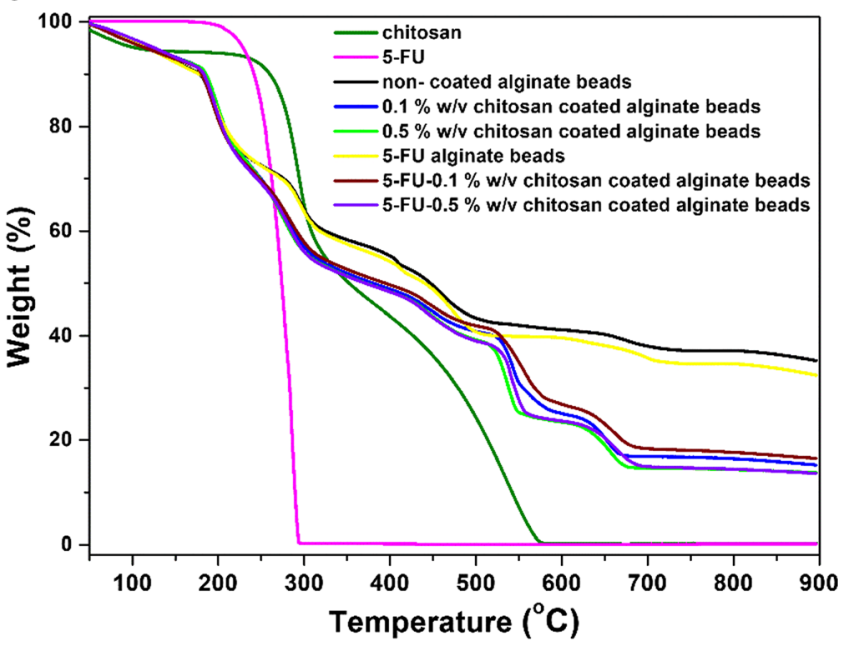

b

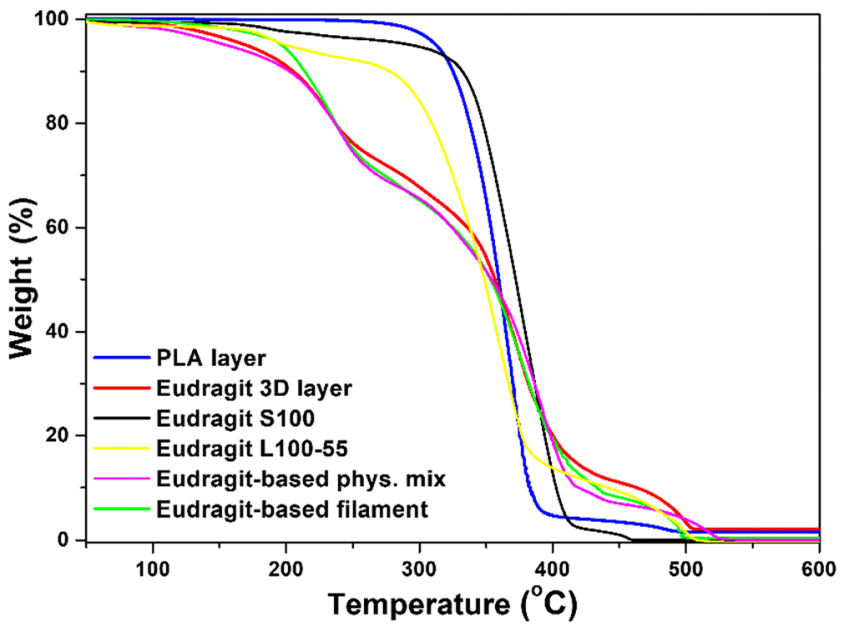

Fig. 4. TGA thermograms of a the raw materials and the alginate bead formulations and $\mathbf{b}$ the raw materials, physical mixture, filament and $3 \mathrm{D}$ printed Eudragit ${ }^{\circledR}$-based layer

The TGA thermograms of Eudragit ${ }^{\circledR} \mathrm{S} 100$ and Eudragit ${ }^{\circledR}$ L100-55 demonstrated $0.4 \%$ and $1.5 \%$ weight loss, respectively, at the temperature range between 40 and $100{ }^{\circ} \mathrm{C}$, attributed to water evaporation as shown in Fig. $4 \mathrm{~b}$ (28). At the same temperature range, the physical mixture of the compounds showed a $1.7 \%$ water loss, whereas HME filament and 3D printed Eudragit ${ }^{\circledR}$-based layer presented $0.4 \%$ and $0.9 \%$ water loss, respectively, probably due to evaporation of a fraction of the contained water during HME and printing procedures. Percent weight loss for both Eudragit ${ }^{\circledR}$ S100 and Eudragit ${ }^{\circledR}$ L100-55 at temperatures above $160{ }^{\circ} \mathrm{C}$ was attributed to polymer degradation (28). The mass loss $(3-5 \%)$ observed between $100{ }^{\circ} \mathrm{C}$ and $185{ }^{\circ} \mathrm{C}$ for the physical mixture, Eudragit $\AA$-based filament and $3 \mathrm{D}$ printed layer can be possibly attributed to TEC evaporation (19). Despite the fact that printing temperature is slightly higher $\left(182{ }^{\circ} \mathrm{C}\right)$ than these temperatures, very short filament residence time inside the printhead does not appear to induce noticeable degradation of the polymers $(19,22)$. This could be verified by the fact that no discoloration of the Eudragit ${ }^{{ }^{\circledR}}$ based layer was observed, distinctive broad Eudragit ${ }^{\circledR}$ XRD halo peaks were still present in the printed Eudragit ${ }^{\circledR}$-based layer and printed Eudragit ${ }^{\circledR}$ retained its pH-responsive nature, as verified by dissolution tests. PLA filament shows no noticeable mass loss till printing temperature $\left(215^{\circ} \mathrm{C}\right)$.

\section{Differential Scanning Calorimetry}

The differential scanning calorimetry (DSC) thermograms of all samples are demonstrated in Fig. 5. Pure Eudragit ${ }^{\circledR}$ S100, Eudragit ${ }^{\circledR}$ L100-55 and F3 physical mixture exhibited a broad endotherm at the temperature range between 50 and $100{ }^{\circ} \mathrm{C}$, attributed to water evaporation. Eudragit ${ }^{\circledR}$ S100 and Eudragit ${ }^{\circledR}$ L100-55 showed an endothermic peak at 218 and $203{ }^{\circ} \mathrm{C}$, respectively $(37,38)$. For F3 Eudragit ${ }^{\circledR}$-based filament, a broad decomposition endotherm was observed at $217^{\circ} \mathrm{C}$. PLA showed a minor glass transition at $59{ }^{\circ} \mathrm{C}$, followed by cold crystallization at $107{ }^{\circ} \mathrm{C}$ and a melting endothermic peak at $149{ }^{\circ} \mathrm{C}(39)$.

\section{X-ray Powder Diffraction}

The X-ray diffractograms of the raw materials and the non-coated and chitosan-coated alginate beads are shown in Fig. 6a. The X-ray powder diffraction (XRD) spectrum of 5FU shows the characteristic diffraction peak of the crystalline drug at $28.26^{\circ}(40)$. The halo pattern in the diffractogram of chitosan $\left(13^{\circ}, 19.8^{\circ}\right)(41)$ is indicative of its semi-crystalline nature (42), while the absence of diffraction peaks in the pattern of sodium alginate is indicative of its amorphous nature. No characteristic peaks of crystalline 5-FU were detected in the diffractograms of the alginate bead formulations, suggesting either the presence of the drug in an amorphous state or a drug concentration below the detection limit of the instrument.

The XRD patterns of Eudragit ${ }^{\circledR}$ S100 and Eudragit ${ }^{\circledR}$ L100-55 displayed broad double or single halos, respectively $\left(13.8^{\circ}, 30.5^{\circ}\right.$ for $\mathrm{S} 100(43)$ and $13.8^{\circ}$ for L100-55 (27)) which are characteristic of the amorphous nature of the polymers (Fig. 6b). The same amorphous pattern was also observed in the physical mixtures, the HME filament and the 3D printed bottom layer of the dosage form.

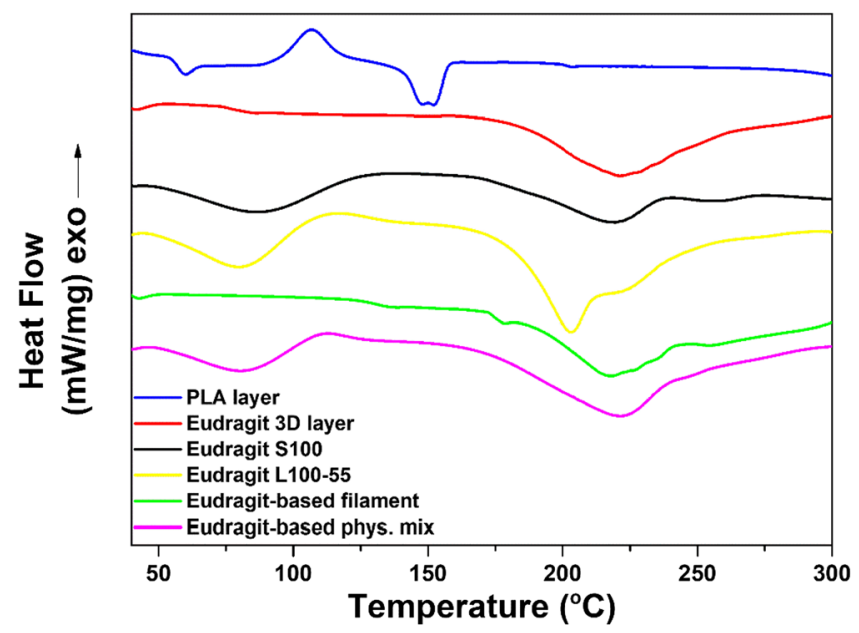

Fig. 5. DSC thermograms of the raw materials, physical mixture, filament and 3D printed Eudragit ${ }^{\circledR}$-based layer 


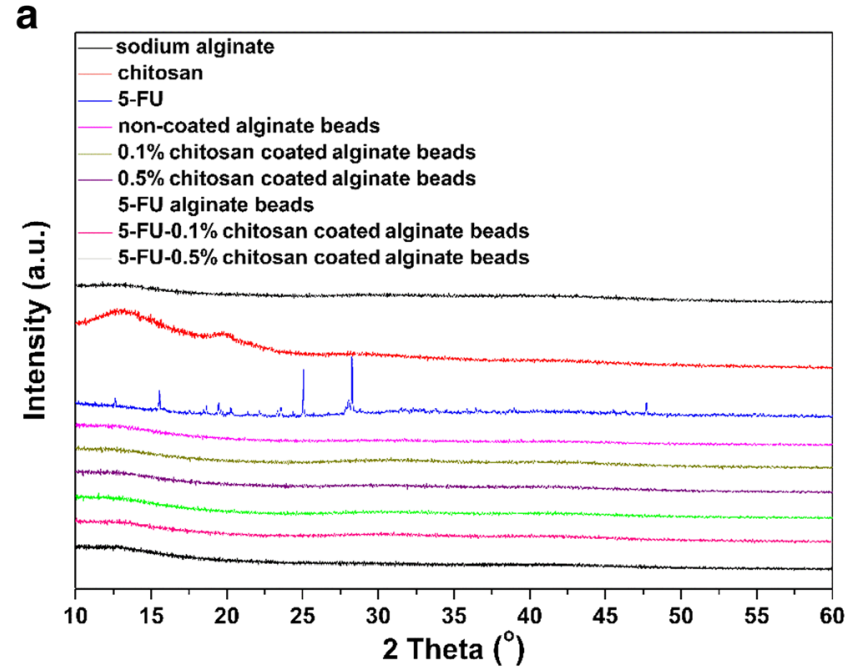

b

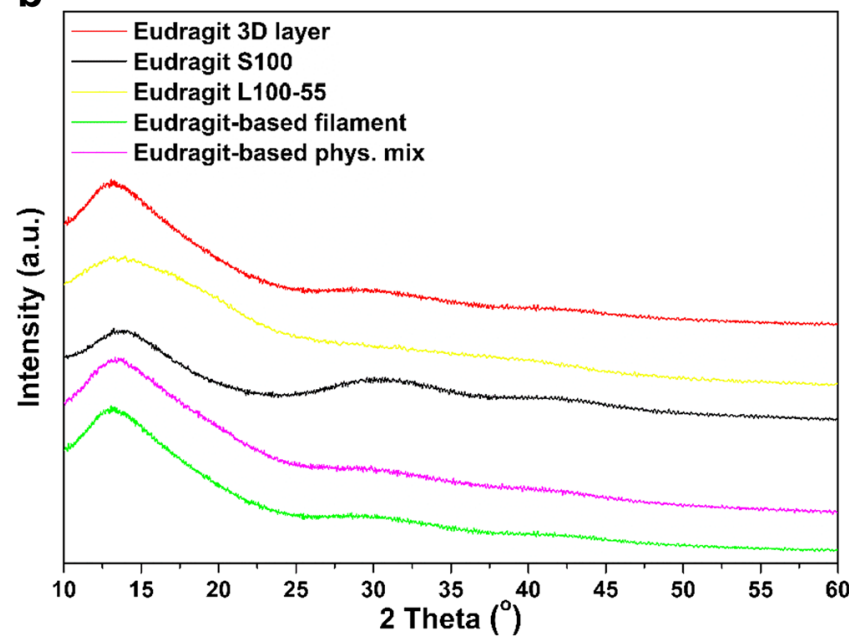

Fig. 6. XRD diffractograms of a the raw materials and the alginate bead formulations and $\mathbf{b}$ the raw materials, physical mixture, filament and 3D printed Eudragit $®$-based layer

\section{Mechanical Tests}

The force-depth curves from the loading-unloading indentation measurements of filaments with PLA and the five different formulations are shown in Fig. 7. The indentation force-penetration depth curves for all materials evaluated indicated creep phenomenon of the specimen at the peak force of $208 \mathrm{mN}$. There were no significant differences in creep behavior among the samples, while no discontinuities or steps were found on the loading curves, suggesting that no cracks were formed during indentation. The indentation depths at the peak load ranged approximately between 6.5 and $11.5 \mu \mathrm{m}$. As the weight percentage of Eudragit ${ }^{\circledR}$ L100-55 decreased, slightly higher indentation depths were observed. F4 (25 wt\% TEC) showed the highest indentation depth and higher plastic work done as revealed by the increased area enclosed between the loading and unloading curve. In contrary, a similar softening behavior was not observed for F5 despite the addition of $35 \% w / w$ TEC. The combination of a high Eudragit ${ }^{\circledR}$ S100 percentage $(65 \% \mathrm{w} / \mathrm{w})$ and $0 \% \mathrm{w} / \mathrm{w}$ Eudragit ${ }^{\circledR}$ L100-55 leads to low indentation depth and small plastic work done.

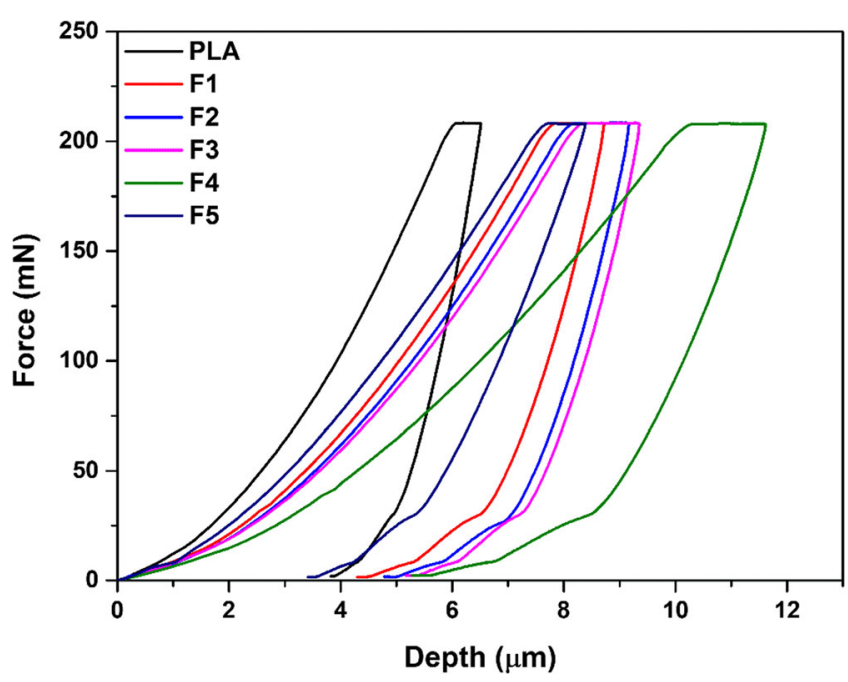

Fig. 7. Typical force-depth curves of PLA and the five different filament formulations

The hardness values though demonstrated a minor decreasing trend as Eudragit ${ }^{\circledR}$ L100-55 weight percentage decreased and Eudragit ${ }^{\circledR}$ S100 increased (Fig. 8a). The
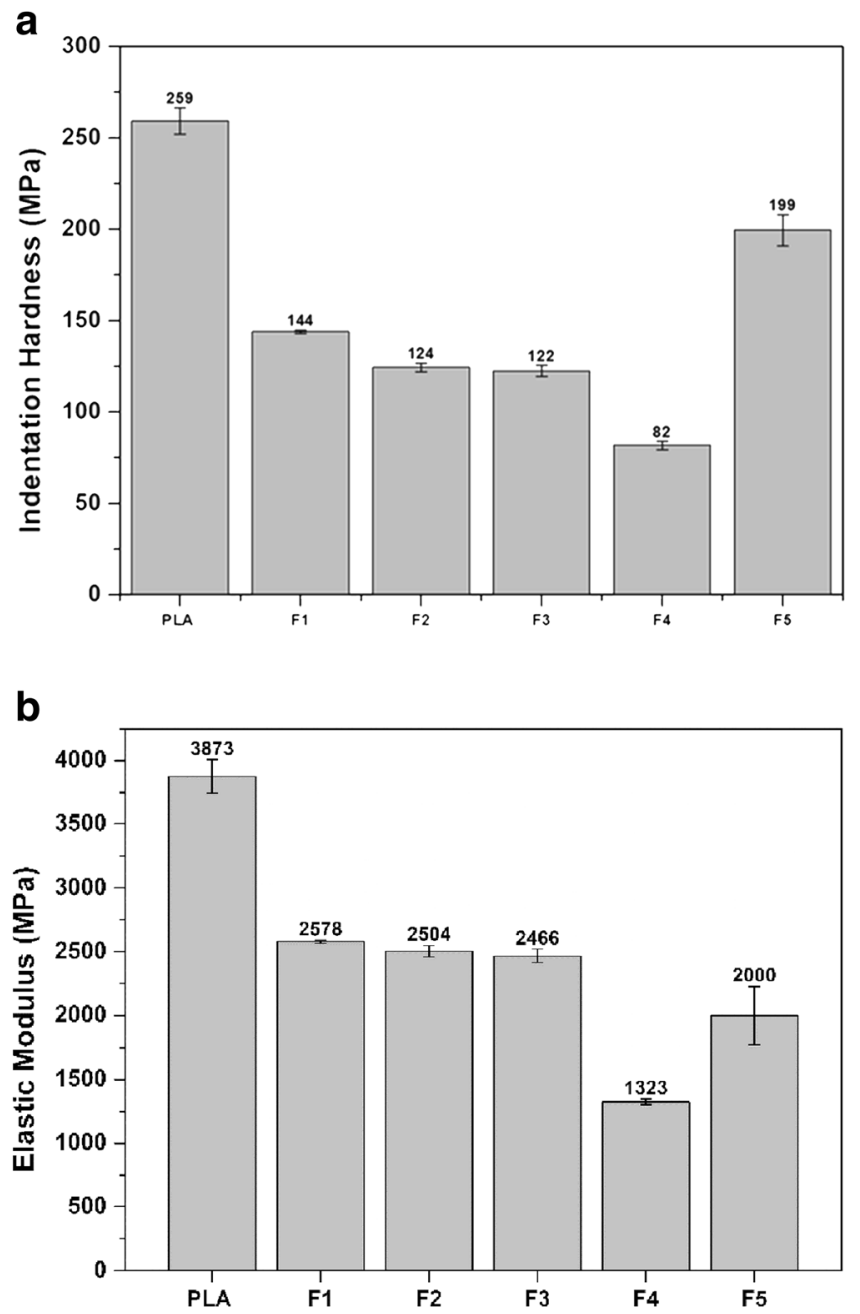

Fig. 8. a Hardness and $\mathbf{b}$ elastic modulus results obtained from the loading-unloading indentation curves for PLA and the five different filament formulations 
increase of TEC content from $22 \%$ to $25 \% w / w$ for $\mathrm{F} 4$ induced a significant decrease $(t$ test, $p<0.05)$ in the elastic modulus and the hardness to 1323 and $82 \mathrm{MPa}$, respectively. Further increase of TEC content to $35 \% w / w$, absence of Eudragit ${ }^{\circledR}$ L100-55 and a significant increase in Eudragit ${ }^{\circledR}$ $\mathrm{S} 100$ content to $65 \% w / w$ in $\mathrm{F} 5$ altered the mechanical response of the material, as the elastic modulus increased achieving values similar to those of the PLA material. The indentation moduli for F1, F2 and F3 were almost the same (ca. $2500 \mathrm{MPa}$ ) as shown in Fig. 8b.

Generally, an increase in hardness renders filaments less prone to localized damage that could lead to premature fracture by the feeding gears inside the printhead and therefore increases their printability. Additionally, a reduction in elastic modulus indicates an overall reduction of filament stiffness. Reduced filament stiffness is beneficial for the purpose of printability, since it allows the filament to be deformed easily without breakage. As a result, we can consider that the printability of filaments can be represented by the ratio Printability $=$ Elastic modulus/Hardness. Such equation shows that the lower values indicate hard and elastic filaments with increased printability. In our case, the above ratio varied between 20.1 (F3) and 10 (F5), and taking into consideration the fact that all filament types were printable, we can assume that filaments exhibiting values lower than 20 are printable. It is also evident that filament deriving from F5 exhibited better printability in comparison to the marketed PLA filament. The above is considered valid at the region of the elasticity and hardness values measured in the study (materials exhibiting extreme hardness or elasticity values cannot be evaluated likewise).

To assess the mechanical strength of the 3D printed materials, a typical tensile test was performed with 3D printed specimen dimensions as shown in Fig. 9. In the same figure, a PLA 3D printed specimen is compared with a 3D printed specimen made from F3 filament using low-magnification optical microscopy. The conditions of 3D printing were the same as those used to $3 \mathrm{D}$ print the dosage forms. Three shells and four $3 \mathrm{D}$ printed layers were utilized. There is a marked difference of stress-strain curves under tension between PLA and F3. The PLA tensile specimen, following yielding, has shown detachment of the shells with maximum strength of
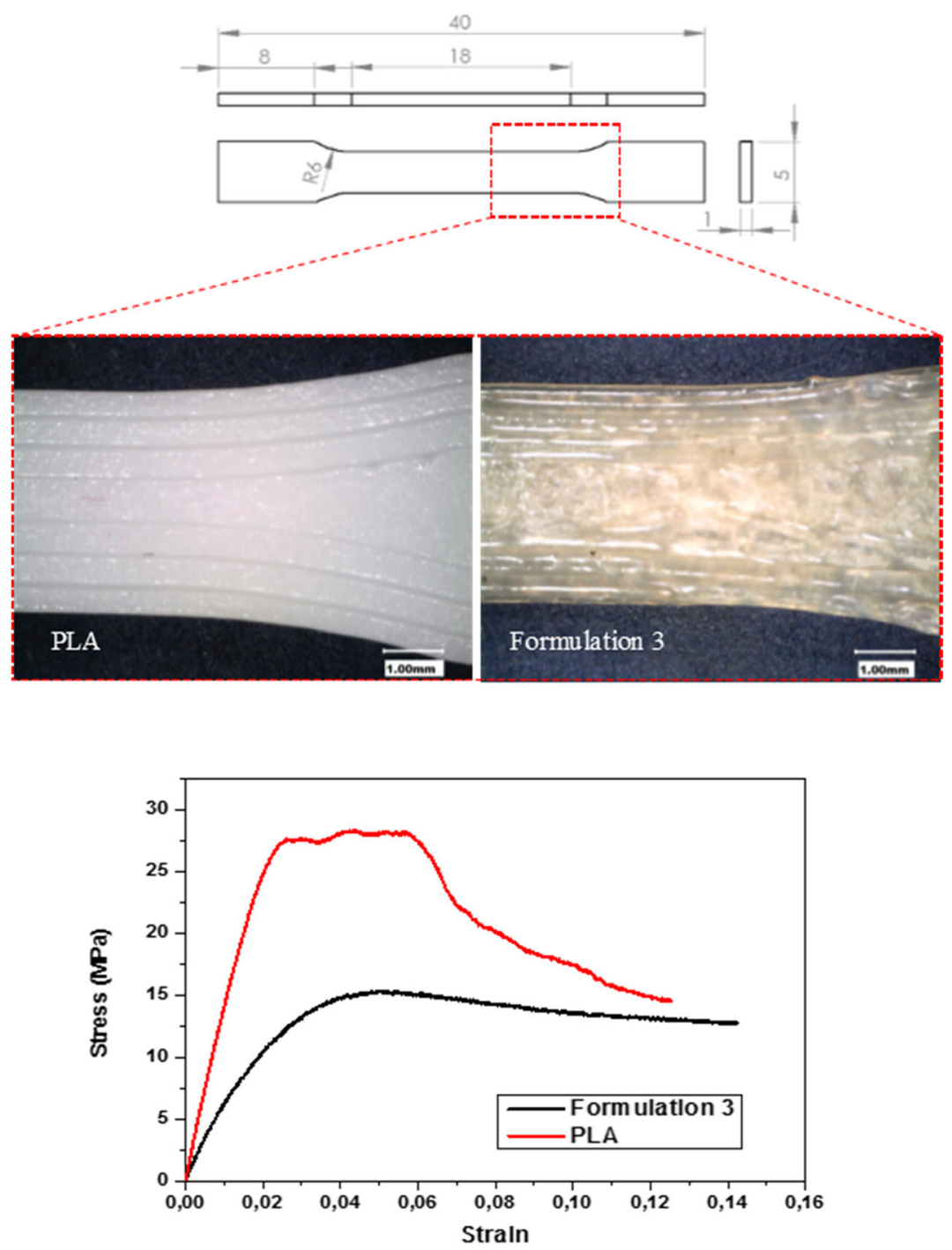

Fig. 9. Typical tensile stress-strain curves with specimen dimensions and optical microscope images of PLA and F3 specimens 
$28 \mathrm{MPa}$ at a strain value of 0.04 , until ultimately failure at much lower stress values. The tensile specimens made from F3 filaments did not show any shell separation following yielding with maximum strength of $15 \mathrm{MPa}$ at a strain value of 0.04 , until ultimately failure at a slightly higher strain level compared to PLA. The modulus was measured to be $1512 \mathrm{MPa}$ for PLA and 0.679 MPa for F3.

\section{Swelling Studies}

The swelling profiles of the non-coated and chitosancoated dry alginate beads in SGF pH 1.2, SIF pH 6.8 and PBS pH 7.4 are shown in Fig. 10. In acidic conditions (Fig. 10a), negligible weight changes were observed for all alginate bead formulations. At $\mathrm{pH} 1.2$, the carboxylic groups of alginate remain protonated forming a tight polymeric network, thus hindering water uptake and swelling of the non-coated alginate beads. Chitosan-coated alginate beads $(0.1 \% \mathrm{w} / \mathrm{v})$

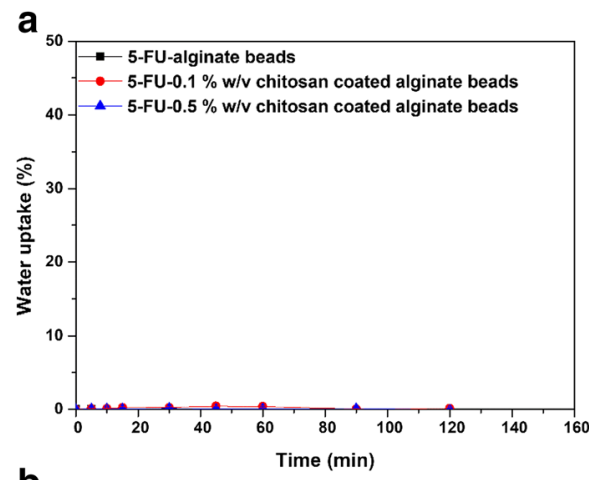

b
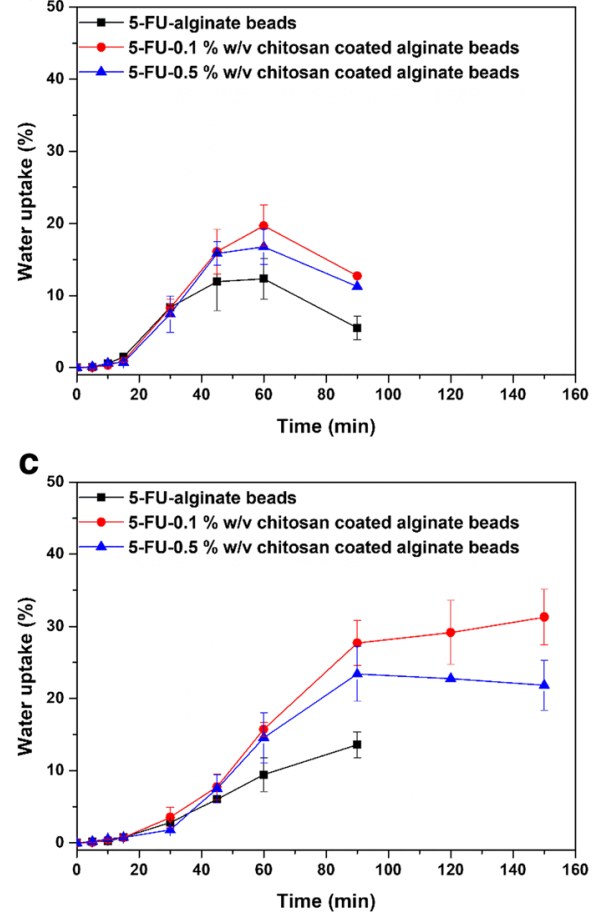

Fig. 10. Swelling profiles of the dry non-coated and chitosan-coated alginate beads in a SGF pH 1.2, b SIF pH 6.8 and $\mathbf{c}$ PBS pH 7.4. Data are presented as mean values \pm standard deviation (S.D.) of three experiments showed a minor weight increase possibly attributed to the polyelectrolyte solubility in acidic media (44).

In conditions simulating the intestinal environment $(\mathrm{pH}$ 6.8), non-coated alginate beads demonstrated a swelling increment. This phenomenon is attributed to the repulsive forces developed between the ionized carboxylic groups of the alginate, which in turn result in a loosening of the polymer structure, favoring water absorption. Interestingly, the swelling degree of both chitosan-coated alginate bead formulations $(0.1 \% w / v$ and $0.5 \% w / v)$ also exhibited a significant increase. At $\mathrm{pH}$ values above 6.0, deprotonation of the amino groups of chitosan occurs, resulting in dissociation of the ionic complex interactions between alginate and chitosan (14). For all alginate bead formulations, water uptake occurred till $90 \mathrm{~min}$, with the swelling degree decreasing thereafter, because of the bead disintegration in the medium as a result of calcium ion exchange with sodium ions of the medium (45).

Similar observations were made for the swelling behavior of alginate bead formulations at $\mathrm{pH}$ 7.4. Non-coated alginate beads fully disintegrate after $90 \mathrm{~min}$, whereas $0.1 \% \mathrm{w} / \mathrm{v}$ and $0.5 \% \mathrm{w} / \mathrm{v}$ coated alginate beads retain their stability until 180 and $150 \mathrm{~min}$, respectively. The higher chitosan content in the beads resulted in a lower swelling degree, possibly attributed to the higher crosslinking density and the lower macromolecular chain mobility, as previously reported (46).

\section{In Vitro Release of 5-FU from Alginate Beads and 3D Printed Dosage Forms Loaded with Alginate Beads}

Release studies were conducted in SGF pH 1.2, SIF pH 6.8 and $\mathrm{PBS}$ pH 7.4 at $37{ }^{\circ} \mathrm{C}$ in an orbital shaking water bath. The release profiles of 5 -FU from the non-coated and chitosan-coated dry alginate beads are shown in Fig. 11. A burst release effect of 5-FU from both non-coated and chitosan-coated alginate beads was observed within the first $15 \mathrm{~min}$ in all media, possibly due to the presence of the drug on the surface of the beads (35) (Fig. 11a-c). This effect was more pronounced for the non-coated alginate beads which also demonstrated a higher rate of 5-FU release in all media ( $t$ test, $p<0.05$ ), as opposed to the chitosan-coated alginate beads.

It has been previously demonstrated that the interaction of $-\mathrm{NH}_{3}$ groups of chitosan with the $-\mathrm{COOH}$ of alginic acid results in the formation of a complex mesh structure inducing a slight retardation of the diffusion rate of 5-FU from the polymer matrix. Similar results on the effect of chitosan coating on the rate of 5-FU release from alginate beads have been previously generated by Yu et al. (13).

3D printed dosage forms deriving from $\mathrm{F} 4$ and $\mathrm{F} 5$ (containing $25 \% \mathrm{w} / \mathrm{w}$ and $65 \% \mathrm{w} / \mathrm{w}$ Eudragit ${ }^{\circledR}$ S100, respectively) did not show any drug release during the experimental time course, as their polymethacrylate surface did not erode completely (no lesions observed). On the contrary, 3D printed dosage forms with filaments corresponding to F1 and F2 (containing $0 \% w / w$ and 5\% $w / w$ Eudragit ${ }^{\circledR}$ S100, respectively) eroded very fast, releasing their content prematurely [50\% release after $c a .180 \mathrm{~min}$ for $\mathrm{F} 1$ and $c a .270 \mathrm{~min}$ for F2 (results not shown)] (47).

In vitro release studies of 5-FU from the F3 3D printed dosage forms containing the non-coated and chitosan-coated 
a

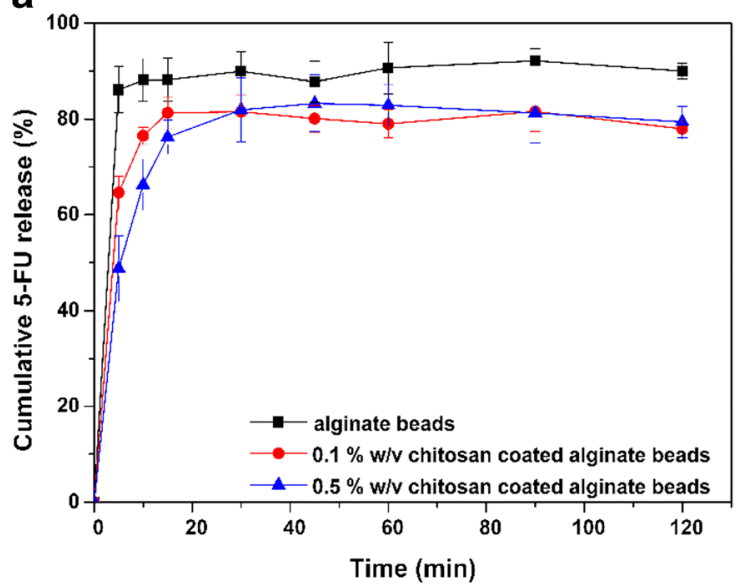

C

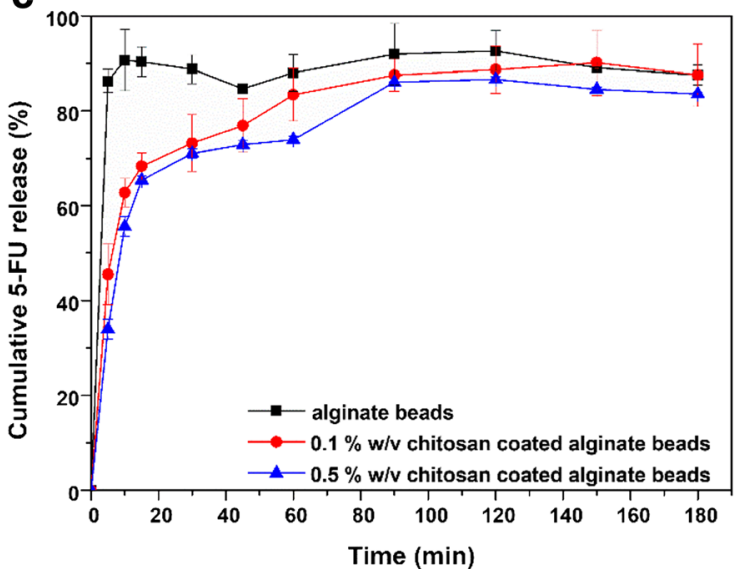

b

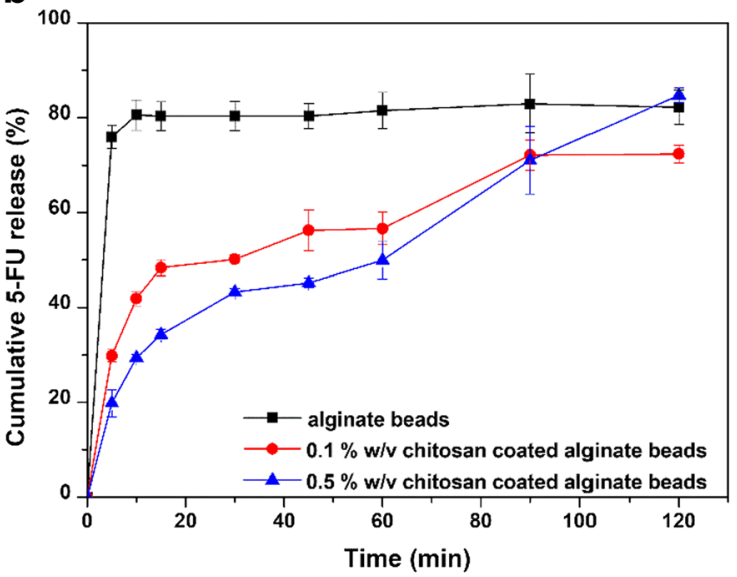

d

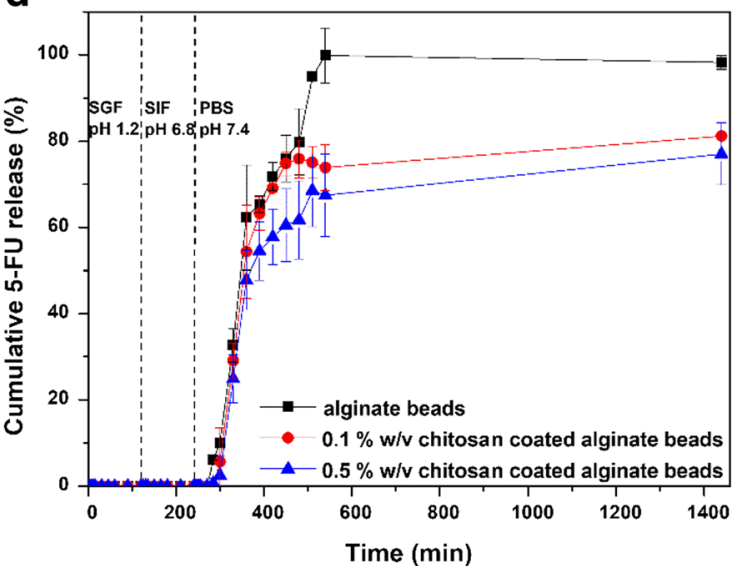

Fig. 11. Cumulative (\%) 5-FU release from the dry non-coated and chitosan-coated $(0.1$ and $0.5 \% w / v)$ alginate beads in a SGF pH 1.2, b SIF pH 6.8 and c PBS pH 7.4 media. d Cumulative (\%) 5-FU release from the 3D printed dosage form (F3 filament) containing the non-coated and chitosan-coated alginate beads. The in vitro release study was conducted in SGF $\mathrm{pH}$ 1.2 during the first $2 \mathrm{~h}$, in SIF pH 6.8 during the next $2 \mathrm{~h}$ and in PBS pH 7.4 till the end of experiment at $24 \mathrm{~h}$ and at $37^{\circ} \mathrm{C}$. Data are presented as mean values \pm standard deviation (S.D.) of three experiments

alginate beads are shown in Fig. 11d. Similar release profiles were recorded for all formulations over the first $120 \mathrm{~min}$ of their residence at $\mathrm{pH} 7.4$, with approximately $40 \%$ of the incorporated drug being released. Observations over $9 \mathrm{~h}$ revealed distinct differences in 5-FU release profiles. Under the adopted experimental protocol, solid dosage forms containing the non-coated alginate beads showed $100 \%$ drug release, whereas corresponding drug release for the chitosancoated beads was of the order of $80 \%$ at the same timescale. Generally, non-coated alginate beads show a faster 5-FU release from the $3 \mathrm{D}$ printed dosage forms, although differences were not statistically significant $(t$ test, $p>0.05)$. Differences become significant at the end of the release tests (after $8 \mathrm{~h}$ ), where non-coated alginate beads still present high drug release, whereas chitosan-coated beads appear to have reached a plateau.

These results indicate that the erosion of Eudragit ${ }^{\circledR}$ based layer enables the release of 5-FU in a controlled manner, after subsequent beads' wetting. Any deviations observed in 5-FU release can be attributed to deviations in custom-made filament diameter, which might have resulted in dosage forms with slightly different Eudragit@-based layer thickness.

\section{Time-Lapsed X-ray Microfocus Computed Tomography}

The results of the time-lapsed microfocus computed tomography $(\mu \mathrm{CT})$ imaging are summarized in Fig. 12. Top row shows Sum along the Rays renderings of the printed dosage form at its initial (dry) state, and after its exposure to different media, while bottom row shows Sum along the Rays renderings through the Eudragit ${ }^{\circledR}$ layer only, before and after the $9 \mathrm{~h}$ exposure of the pill to the various solutions.

Sum along the Rays rendering casts one ray per display pixel into the dataset and renders the cumulative intensity (sum of grey values) of all voxels (3D pixel) along that pixeldefined line. The higher the integrated opacity of these voxels is along a given ray, the brighter the corresponding pixel in the rendered image. In simple terms, Sum along the Rays can be interpreted as an "inverse virtual radiograph" of the specimen along the axis that is normal to the screen/paper. This representation enables qualitative $2 \mathrm{D}$ mapping of the attenuation measured over the whole thickness of the specimen, providing an overview of the specimen's morphology.

The Sum along the Rays renderings through the whole printed dosage form (Fig. 12-top row) revealed that the 


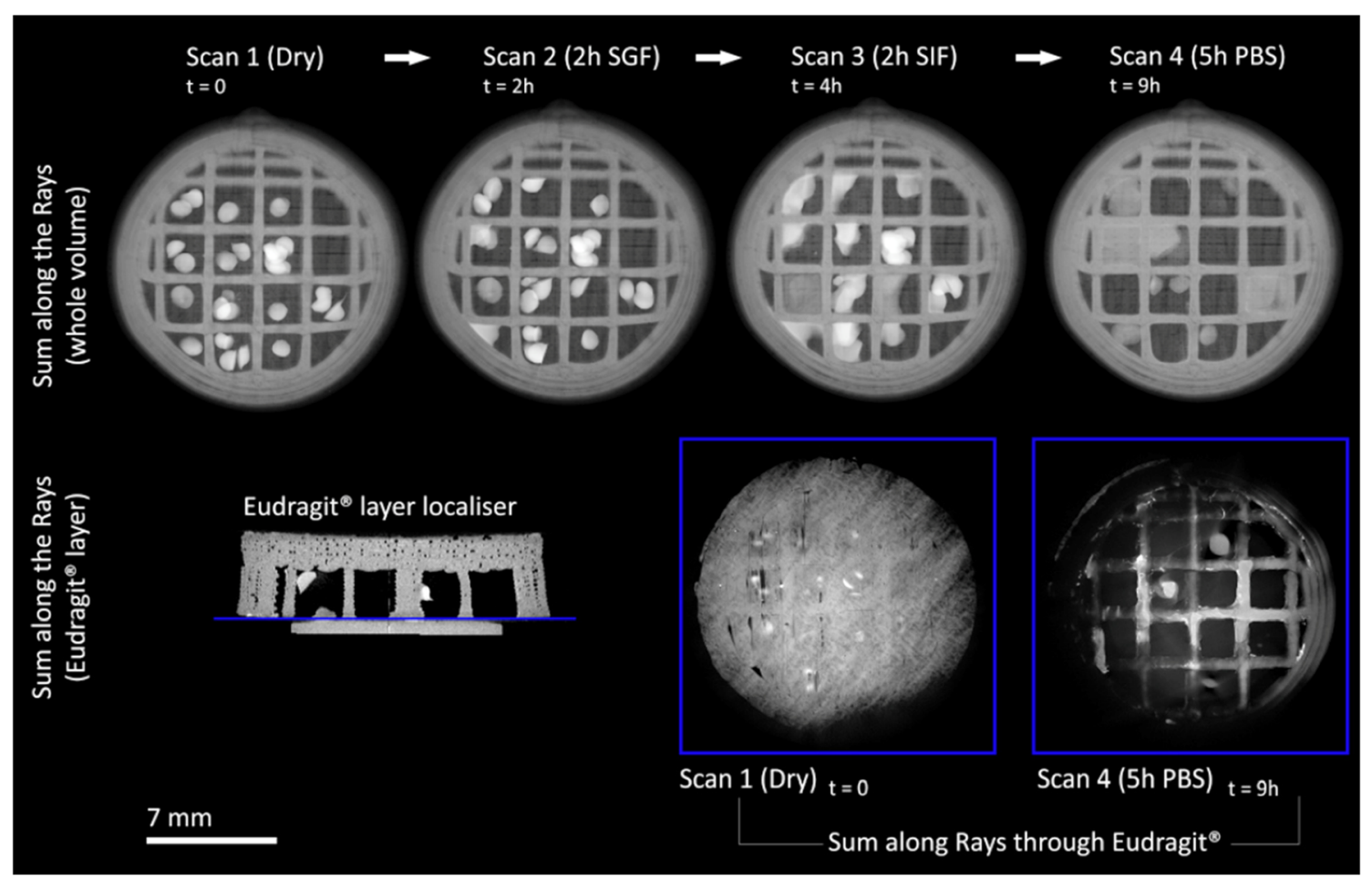

Fig. 12. Time-lapsed $X$-ray microfocus computed tomography $(\mu \mathrm{CT})$. Top row: Sum along the Rays renderings of the printed dosage form at its initial/dry state (scan 1), after 2-h exposure to SGF (scan 2), consequent 2-h exposure to SIF (scan 3), followed by 5-h exposure to PBS (scan 4). Bottom row: Sum along the Rays renderings through the Eudragit ${ }^{\circledR}$-based layer only, before and after the 9-h exposure of the pill to the various solutions

beads in scan 2 appear comparable in density (brightness), size and shape to their initial/dry state shown in scan 1 . No swelling of the alginate beads was observed after the initial 2$\mathrm{h}$ exposure in SGF. Upon consequent exposure to SIF for $2 \mathrm{~h}$, the beads appeared enlarged and started losing their shape, which implies that swelling possess is initiated, possibly due to slow intrusion of the dissolution medium inside the matrix. After the final 5-h exposure in PBS, most of the alginate beads appear to have escaped the printed container, and the remaining one appears completely collapsed. The fact that these remaining beads in scan 4 appear darker than the beads in scans 1, 2 and 3 implies that these are thin alginate residual layers, rather than well-formed particles.

The bottom row in Fig. 12 focuses on the thin Eudragit ${ }^{\circledR}$ layer and shows Sum along the Rays renderings of it before and after the 9-h exposure of the dosage form to the various solutions. These images show that by the end of the fifth hour in PBS, the Eudragit ${ }^{\circledR}$ layer is completely dissolved and the cells that contained the alginate beads are now fully open, having released almost all the containing beads.

It should be noted that the initial swelling of the beads in the SIF is not caused by rapid intrusion of dissolution medium inside the matrix, rather than by slow capillary flow of a small quantity of dissolution medium, that causes an initial swelling and transforms beads to gel-like masses. Dissolution tests showed that 5-FU was not leaking towards the dissolution medium before the complete erosion of the bottom Eudragit ${ }^{\circledR}$-based layer. A possible explanation for this behavior is that the diffusion of 5-FU through these gel-like masses is very slow and also diffusion through the still intact Eudragit ${ }^{\circledR}$-based layer is hindered by the fact that both 5 -FU and Eudragit ${ }^{\circledR}$ are predominantly negatively charged at neutral $\mathrm{pH}$, so repulsion between them prevents the diffusion of 5-FU towards the dissolution medium.

\section{CONCLUSIONS}

In the present study, we demonstrated the feasibility of fabricating a $\mathrm{pH}$-responsive dosage form by means of FDM $3 \mathrm{D}$ printing for the site-specific delivery of the cytostatic 5FU for colon cancer treatment. The formulation comprised of an insoluble PLA upper compartment and a thin bottom layer consisting of a mixture of polymethacrylates with $\mathrm{pH}$ dependent solubility. In vitro release studies showed that the formulation can efficiently deliver 5-FU-loaded alginate beads at $\mathrm{pH}$ values corresponding to the colonic environment, whereas the $\mathrm{pH}$-responsive design of the dosage form might minimize the impact of potential manufacturing defects, reducing the possibility of dose dumping. Release of the API from the beads was rapid and consistent, whereas $\mathrm{pH}$-dependent dissolution of the protective polymethacrylate barrier might enable colon-specific drug delivery with minimal deviations. Combining the above with the ability of $3 \mathrm{D}$ printing to easily create personalized medicines by adjusting the dose of the incorporated API's, the aforementioned dosage forms merit further investigation.

\section{ACKNOWLEDGEMENTS}

The authors would like to acknowledge $\mu$-VIS X-Ray Imaging Centre and the Biomedical Imaging Unit at the 
University of Southampton for provision of tomographic imaging facilities, as well as Nikon Metrology UK Ltd for the provision of the Med-X prototype scanner.

\section{COMPLIANCE WITH ETHICAL STANDARDS}

Conflict of Interest The authors declare that they have no conflict of interest.

\section{REFERENCES}

1. Fina F, Goyanes A, Gaisford S, Basit AW. Selective laser sintering (SLS) 3D printing of medicines. Int $\mathrm{J}$ Pharm. 2017;529:285-93.

2. Wang J, Goyanes A, Gaisford S, Basit AW. Stereolithographic (SLA) 3D printing of oral modified-release dosage forms. Int J Pharm. 2016;503:207-12.

3. Goyanes A, Wang J, Buanz A, Martinez-Pacheco R, Telford R, Gaisford S, et al. 3D printing of medicines: engineering novel oral devices with unique design and drug release characteristics. Mol Pharm. 2015;12:4077-84.

4. Gioumouxouzis CI, Katsamenis OL, Bouropoulos N, Fatouros DG. 3D printed oral solid dosage forms containing hydrochlorothiazide for controlled drug delivery. J Drug Deliv Sci Technol. 2017;40:164-71.

5. Chai X, Chai H, Wang X, Yang J, Li J, Zhao Y, et al. Fused deposition modeling (FDM) 3D printed tablets for intragastric floating delivery of domperidone. Sci. Rep. [Internet]. 2017;7:2829. Available from: http://www.nature.com/articles/ s41598-017-03097-x.

6. Holländer J, Genina N, Jukarainen H, Khajeheian M, Rosling A, Mäkilä E, et al. Three-dimensional printed PCL-based implantable prototypes of medical devices for controlled drug delivery. J Pharm Sci. 2016;105:2665-76.

7. Markl D, Zeitler JA, Rasch C, Michaelsen MH, Müllertz A, Rantanen J, et al. Analysis of 3D prints by X-ray computed microtomography and terahertz pulsed imaging. Pharm Res. 2017;34:1037-52.

8. Beck RCR, Chaves PS, Goyanes A, Vukosavljevic B, Buanz A, Windbergs $\mathrm{M}$, et al. 3D printed tablets loaded with polymeric nanocapsules: an innovative approach to produce customized drug delivery systems. Int J Pharm. 2017;528:268-79.

9. Lee YE, Kim H, Seo C, Park T, Lee KB, Yoo SY, et al. Marine polysaccharides: therapeutic efficacy and biomedical applications. Arch Pharm Res. 2017;40:1006-20.

10. Ohya Y, Takei T, Kobayashi H, Ouchi T. Release behaviour of 5-fluorouracil from chitosan-gel microspheres immobilizing 5fluorouracil derivative coated with polysaccharides and their cell specific recognition. J Microencapsul. 1993;10:1-9.

11. Akbuǵa J, Bergişadi N. 5-Fluorouracil-loaded chitosan microspheres: preparation and release characteristics. J Microencapsul. 1996;13:161-8.

12. Ramdas M, Dileep KJ, Anitha Y, Paul W, Sharma CP. Alginate encapsulated bioadhesive chitosan microspheres for intestinal drug delivery. J Biomater Appl. 1999;13:290-6.

13. Yu CY, Zhang XC, Zhou FZ, Zhang XZ, Cheng SX, Zhuo RX. Sustained release of antineoplastic drugs from chitosanreinforced alginate microparticle drug delivery systems. Int J Pharm. 2008;357:15-21.

14. Glavas Dodov M, Calis S, Crcarevska MS, Geskovski N, Petrovska V, Goracinova K. Wheat germ agglutininconjugated chitosan-Ca-alginate microparticles for local colon delivery of 5-FU: development and in vitro characterization. Int J Pharm. 2009;381:166-75.

15. Glavas-Dodov M, Steffansen B, Crcarevska MS, Geskovski N, Dimchevska S, Kuzmanovska S, et al. Wheat germ agglutininfunctionalised crosslinked polyelectrolyte microparticles for local colon delivery of 5-FU: in vitro efficacy and in vivo gastrointestinal distribution. J Microencapsul. 2013;30:643-56.

16. Li G, Song S, Zhang T, Qi M, Liu J. PH-sensitive polyelectrolyte complex micelles assembled from CS-g-PNIPAM and ALG-g$\mathrm{P}(\mathrm{NIPAM}-\mathrm{co}-\mathrm{NVP})$ for drug delivery. Int $\mathrm{J}$ Biol Macromol. 2013;62:203-10.

17. Di Martino A, Pavelkova A, Maciulyte S, Budriene S, Sedlarik V. Polysaccharide-based nanocomplexes for co-encapsulation and controlled release of 5-fluorouracil and temozolomide. Eur J Pharm Sci. 2016;92:276-86.

18. Lakkakula JR, Matshaya T, Krause RWM. Cationic cyclodextrin/alginate chitosan nanoflowers as 5-fluorouracil drug delivery system. Mater Sci Eng C. 2017;70:169-77.

19. Okwuosa TC, Pereira BC, Arafat B, Cieszynska M, Isreb A, Alhnan MA. Fabricating a shell-core delayed release tablet using dual FDM 3D printing for patient-centred therapy. Pharm Res. 2017;34:427-37.

20. Zhang J, Feng X, Patil H, Tiwari RV, Repka MA. Coupling 3D printing with hot-melt extrusion to produce controlled-release tablets. Int J Pharm. 2017;519:186-97.

21. Sadia M, Sośnicka A, Arafat B, Isreb A, Ahmed W, Kelarakis A, et al. Adaptation of pharmaceutical excipients to FDM 3D printing for the fabrication of patient-tailored immediate release tablets. Int J Pharm. 2016;513:659-68.

22. Pietrzak K, Isreb A, Alhnan MA. A flexible-dose dispenser for immediate and extended release 3D printed tablets. Eur J Pharm Biopharm. 2015;96:380-7.

23. Gioumouxouzis CI, Baklavaridis A, Katsamenis OL, Markopoulou CK, Bouropoulos N, Tzetzis D, et al. A 3D printed bilayer oral solid dosage form combining metformin for prolonged and glimepiride for immediate drug delivery. Eur J Pharm Sci. 2018;120:40-52.

24. Rodríguez M, Vila-Jato JL, Torres D. Design of a new multiparticulate system for potential site-specific and controlled drug delivery to the colonic region. J Control Release. 1998;55:67-77.

25. Krishnaiah YSR, Satyanarayana V, Kumar BD, Karthikeyan RS, Bhaskar P. In vivo pharmacokinetics in human volunteers: oral administered guar gum-based colon-targeted 5-fluorouracil tablets. Eur J Pharm Sci. 2003;19:355-62.

26. Goto T, Tomizawa N, Kobayashi E, Fujimura A. A comparative pharmacology study between the intracolonic and oral routes of 5-FU administration in a colon cancer-bearing Yoshida sarcoma rat model. J Pharmacol Sci. 2004;95:163-73.

27. Chomcharn N, Xanthos M. Properties of aspirin modified enteric polymer prepared by hot-melt mixing. Int J Pharm. 2013;450:259-67.

28. Parikh T, Gupta SS, Meena A, Serajuddin ATM. Investigation of thermal and viscoelastic properties of polymers relevant to hot melt extrusion-III: polymethacrylates and polymethacrylic acid based polymers. J. Excipients Food Chem. 2014;5:56-64.

29. Thoma K, Bechtold K. Influence of aqueous coatings on the stability of enteric coated pellets and tablets. Eur J Pharm Biopharm. 1999;47:39-50.

30. Mansour G, Tzetzis D, Bouzakis KD. A nanomechanical approach on the measurement of the elastic properties of epoxy reinforced carbon nanotube nanocomposites. Tribol Ind. 2013;35:190-9.

31. Tzetzis D, Mansour G, Tsiafis I, Pavlidou E. Nanoindentation measurements of fumed silica epoxy reinforced nanocomposites. J Reinf Plast Compos. 2013;32:160-73.

32. Mansour G, Tzetzis D. Nanomechanical characterization of hybrid multiwall carbon nanotube and fumed silica epoxy nanocomposites. Polym - Plast Technol Eng. 2013;52:1054-62.

33. Katsamenis OL, Olding M, Hutchinson C, Jones GM, Mavrogordato MN, Schneider P, Lackie P, Warner JA, Haig I, Richeldi LSI . Development of X-ray microfocus computer tomography for clinical applications. Pap. Present. 3rd Annu. Futur. Med. - Role Dr. 2027. London, UK; 2017.

34. Schindelin J, Arganda-Carreras I, Frise E, Kaynig V, Longair M, Pietzsch T, et al. Fiji: an open-source platform for biologicalimage analysis. Nat Methods. 2012;9:676-82.

35. Kyzioł A, Mazgała A, Michna J, Regiel-Futyra A, Sebastian V. Preparation and characterization of alginate/chitosan formulations for ciprofloxacin-controlled delivery. J Biomater Appl. 2017:32:162-74. 
36. Sun X, Shi J, Xu X, Cao S. Chitosan coated alginate/poly(Nisopropylacrylamide) beads for dual responsive drug delivery. Int J Biol Macromol. 2013;59:273-81.

37. Lotlikar V, Kedar U, Shidhaye S, Kadam V. PH-responsive dual pulse multiparticulate dosage form for treatment of rheumatoid arthritis. Drug Dev Ind Pharm. 2010;36:1295-302.

38. Chawla A, Sharma P, Pawar P. Eudragit S-100 coated sodium alginate microspheres of naproxen sodium: formulation, optimization and in vitro evaluation. Acta Pharma. 2012;62:529-45.

39. Cao X, Mohamed A, Gordon SH, Willett JL, Sessa DJ. DSC study of biodegradable poly(lactic acid) and poly(hydroxy ester ether) blends. Thermochim Acta. 2003;406:115-27.

40. Moisescu-Goia C, Muresan-Pop M, Simon V. New solid state forms of antineoplastic 5-fluorouracil with anthelmintic piperazine. J Mol Struct. 2017;1150:37-43.

41. Li Y, Xu J, Xu Y, Huang L, Wang J, Cheng X. Synthesis and characterization of fluorescent chitosan-ZnSe/ZnS nanoparticles for potential drug carriers. RSC Adv. 2015;5:38810-7.

42. Nivethaa EAK, Dhanavel S, Narayanan V, Vasu CA, Stephen A. An in vitro cytotoxicity study of 5-fluorouracil encapsulated chitosan/gold nanocomposites towards MCF-7 cells. RSC Adv. 2015;5:1024-32.

43. Sharma M, Sharma V, Panda AK, Majumdar DK. Development of enteric submicron particle formulation of papain for oral delivery. Int J Nanomedicine. 2011;6:2097-111.

44. Kienzle-Sterzer CA, Rodriguez-Sanchez D, Rha CK. Flow behavior of a cationic biopolymer: chitosan. Polym Bull. 1985;13:1-6.

45. Chang JJ, Lee YH, Wu MH, Yang MC, Chien CT. Preparation of electrospun alginate fibers with chitosan sheath. Carbohydr Polym. 2012;87:2357-61.

46. Dey SK, De PK, De A, Ojha S, De R, Mukhopadhyay AK, et al. Floating mucoadhesive alginate beads of amoxicillin trihydrate: a facile approach for $\mathrm{H}$. pylori eradication. Int $\mathrm{J}$ Biol Macromol. 2016;89:622-31.

47. Mehuys E, Remon JP, Vervaet C. Production of enteric capsules by means of hot-melt extrusion. Eur J Pharm Sci. 2005;24:207-12. 